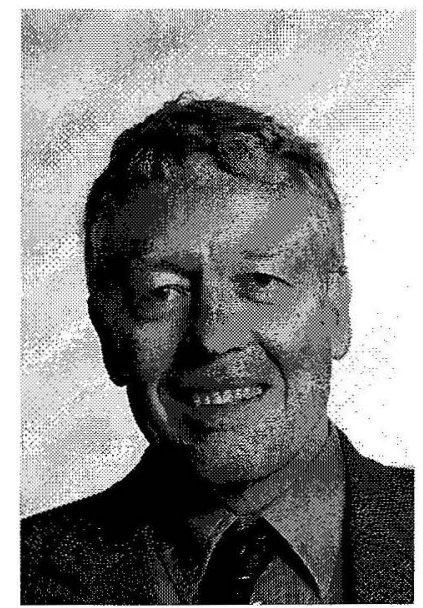

\title{
MIGRATION AND \\ POPULATION FORECASTS \\ FOR THE WESTERN BAY OF \\ PLENTY, 2001-2051: \\ IMPLICATIONS FOR THE \\ LABOUR FORCE AND \\ HOUSEHOLD COMPOSITION
}

\section{R.D. Bedford and A. Dharmalingam}

University of Waikato

\begin{abstract}
The Bay of Plenty Regional Council and the Western Bay and Tauranga District Councils are currently exploring growth options for the period 2001-2051. A critical determinant of their forecasts for the regional economy and the infrastructure and environment that will support significant population growth over the next 50 years is migration. In this paper we explore two different ways of building net migration assumptions into subnational projections. The method currently employed by Statistics New Zealand assumes, by definition, a declining rate of migration for most age groups in a region which is experiencing quite rapid population growth. We examine the implications for projections of the labour force age groups of a method that assumes constant age-specific rates of net migration, rather than constant levels of net migration. The alternative method takes account of the significant changes in the age structure of New Zealand's population over the next 50 years and generates a larger, older workforce (and elderly population) than the method currently employed by Statistics New Zealand. The implications of the different methods of estimating the contribution of net migration to population growth are also explored for household composition over the 50 year period.
\end{abstract}

